\title{
UMA TRAJETÓRIA DISSONANTE: Francisco de Oliveira, a SUDENE e o CEBRAP ${ }^{1}$
}

\author{
Marco Antonio Perruso*
}

\begin{abstract}
Este artigo apresenta um dos mais importantes cientistas sociais brasileiros, Francisco Maria Cavalcanti de Oliveira, mais conhecido como Chico de Oliveira. O fato de ter sido figura destacada da cultura política nacionalista e desenvolvimentista do pré-64 - na SUDENE - e da cultura política crítica deste legado após o golpe - no CEBRAP - consubstancia uma trajetória dissonante, movimentada, por vezes turbulenta. E evidencia o "devir" do espaço social no qual atuava, propiciando uma relativização da dualidade institucional, estilística e ideológica entre estes dois verdadeiros tipos ideais de produção e atuação intelectual. Embora tal dualidade tenha feito toda a diferença para muitos dos que protagonizaram o período que trouxe a substituição de um padrão intelectual e político hegemônico (o ensaísmo engajado à maneira isebiana) por outro (os universitários politizados de origem uspiana), talvez ela não seja tão necessariamente opositiva como estamos acostumados a ler na história de nosso campo intelectual e da institucionalidade das ciências sociais brasileiras.

Palavras Chave: Pensamento Social Brasileiro. Intelectuais. Cultura Política, Francisco de Oliveira.
\end{abstract}

Francisco Maria Cavalcanti de Oliveira, mais conhecido como Chico de Oliveira, um dos mais importantes cientistas sociais brasileiros, possui uma trajetória que ainda não foi investigada sob a perspectiva do pensamento social e político brasileiro da segunda metade do século XX. Oriundo de Pernambuco, onde se formou em Ciências Sociais, trabalhou como economista, atuou profissionalmente no Nordeste em instituições públicas, teve experiências na iniciativa privada e em consultorias internacionais, radicou-se finalmente em São Paulo, onde é Professor Titular de Sociologia na USP. Sua trajetória, muitas vezes, foi diferente das de seus contemporâneos, mesmo tendo participado de organismos tão emblemáticos como a SUDENE e o CEBRAP, que ajudaram a conformar os campos intelectual e político em suas respectivas épocas.

\footnotetext{
* Doutor em Sociologia. Professor Adjunto de Sociologia da Universidade Federal Rural do Rio de Janeiro. BR-465, Km 7. Cep: 23890-000. Seropedica - Rio de Janeiro-Brasil.trogao@bol.com.br

${ }^{1} \mathrm{O}$ presente artigo é um dos resultados do Projeto "Precursores da Sociologia do Trabalho no Brasil", coordenado por José Sergio Leite Lopes (PPGAS/Museu Nacional/UFRJ) por ocasião do Edital "Memória do Saber" do CNPq.
}

Nascido em Recife, em 1933, fez a graduação entre 1952 a 1956. A configuração intelectual e institucional da sociedade pernambucana onde Francisco de Oliveira iniciou sua formação profissional é bem delineada por José Sérgio Leite Lopes como um

pólo de pensamento social no Norte-Nordeste do país, onde o prestígio da Faculdade de Direito e de pensadores que por ela passaram, e, depois, de Gilberto Freyre e sua obra, acabaram por produzir instituições de ensino e pesquisa como a Faculdade de Ciências Sociais do Recife e o Instituto Joaquim Nabuco que coexistiram com as instituições, as iniciativas de pesquisa e os pesquisadores do Rio e de São Paulo nos anos 40, 50 e 60. (Lopes, 2004, p. 3)

O próprio Francisco de Oliveira, em depoimento ao mesmo José Sérgio Leite Lopes, contextualiza o lugar social no qual se fomentou sua vocação intelectual:

[...] todo o ensino no Brasil hoje é julgado a partir do padrão de São Paulo. A gente faz um juízo e vê o ensino nas províncias a partir do padrão de São Paulo, mas o padrão de São Paulo é mítico. E na realidade, nos anos 50, a distância entre São Paulo e as províncias não era tão grande. (Oliveira, 1992, n.p.) 
Enquanto estava na universidade, Francisco de Oliveira já trabalhava no setor bancário. Depois de formado, entra para o Banco do Nordeste: ${ }^{2}$

Mas eu faço uma mudança para economia porque ser sociólogo não enchia a barriga. Antes de concluir o curso eu descobri que não tinha o que fazer com aquilo, aí entrei num concurso do Banco do Nordeste. Exatamente porque a Faculdade de Economia [da Universidade do Recife] não servia para nada e porque não existiam economistas no Brasil (salvo no Rio e ninguém do Rio queria ir para o Nordeste), o Banco do Nordeste fazia uns cursos de treinamento muito rápidos. [...] [Participava] gente formada em Direito, gente formada, como eu, em Ciências Sociais. O banco abria concurso e convidava essas pessoas. [... você escrevia um texto de vinte páginas dizendo por que queria trabalhar para o banco, era um pouco a patriotada nordestina, que queria salvar o Nordeste e tal. [...] Eu fiz um curso de quatro meses intensivo, na Bahia, que foi, na verdade, uma revelação. Meu pobre curso de Ciências Sociais ficou no chinelo diante desse curso do Banco do Nordeste. Foram quatro meses de massacre. Depois disso a gente fez estágio no Rio, na antiga SUMOC, que era a Superintendência da Moeda e do Crédito, ${ }^{3}$ fizemos viagens pelo Nordeste todo, de Fortaleza a Ilhéus por terra. [...] Depois, uma seleção final onde algumas instituições podiam escolher [dentre os cursandos], a gente estava lá como um bando de noivas que podiam ser escolhidas pelos coronéis. [...] Fiquei no Banco do Nordeste, no seu Instituto Técnico de Estudos Econômicos. A sede era em Fortaleza. Saí então do Recife e casei logo, evidentemente porque o meu salário tinha triplicado.

[...] Aí fiquei sem identidade. Eu era formado em Ciências Sociais, mas a especialização era em Economia. (Oliveira, 1992, n.p.)

Essa falta de identidade, mencionada por Francisco de Oliveira, refletia o quão diminuto era, ainda, o campo e o mercado de trabalho das ciências sociais em Pernambuco, bem como no restante do país. Assim, ele e outros cientistas sociais buscavam atuar em órgãos públicos numa perspectiva de diálogo com outras áreas, como a economia e a administração.

Como José Sérgio Leite Lopes aponta - na condição de entrevistador - e como ressalta o próprio Francisco de Oliveira, o Banco do Nordeste baseava-se no modelo representado pelo

${ }^{2}$ O Banco do Nordeste do Brasil é uma sociedade de economia mista, de propriedade da União Federal, criado em 1952.

${ }^{3}$ Órgão público que possuía funções similares às do atual Banco Central do Brasil. Existiu de 1945 a 1965.
BNDES, Banco Nacional de Desenvolvimento Econômico e Social, criado, também, pelo governo federal no mesmo ano de $1952,{ }^{4}$ além de se inspirar na CEPAL - Comissão Econômica para a América Latina e o Caribe (por sua vez criada em 1948 pela ONU). Não por acaso, vários professores atuantes no curso oferecido pelo Banco do Nordeste provinham do BNDES. Outros, da Fundação Getúlio Vargas (FGV). ${ }^{5}$

Tais instituições evidenciavam o processo de complexificação por que passava o Estado brasileiro numa sociedade que se industrializava, bem como os esforços de modernização da administração pública, promovidos por grupos dirigentes durante duas décadas democráticas - 19451964 - da história de nosso país. Nesse período, a preocupação maior era induzir o desenvolvimento nacional a partir do Estado. Outra instituição, típica dessa mesma leva transformadora vivida pela sociedade brasileira, era a Superintendência do Desenvolvimento do Nordeste, SUDENE, criada pelo governo federal em 1959.

Francisco de Oliveira permaneceu dois anos no Banco do Nordeste:

Eu já achava que entendia do mundo, que já sabia o que queria, já avaliava que o Banco do Nordeste não ia dar certo. Fiz a minha própria crítica, pedi demissão e fui-me embora. Voltei para o Recife e lá fiquei em uma Comissão de Desenvolvimento Econômico de Pernambuco, que foi fundada pelo Agamenon Magalhães, mas a Comissão me mandou para o Rio. Então fiz o curso da CEPAL, [...] [que] foi outra revelação porque [...] o curso do Banco do Nordeste era mais tecnocrático [...]. (Oliveira, 1992, n.p.)

No curso organizado pela CEPAL, que durou cerca de seis meses, incluindo estágio, Francisco de Oliveira tem contato com importantes intelectuais que impactaram sua formação:

Tive também um grande professor que era o Jorge Almada ${ }^{6}$ talvez o melhor que já tive. Ele tinha uma elegância, uma fluência, você saia de lá disparado querendo fazer a programação global e querendo

${ }^{4}$ Sua primeira denominação foi BNDE (Banco Nacional de Desenvolvimento Econômico); apenas em 1982, nos estertores do regime militar, passou a ser BNDES.

${ }^{5}$ A FGV foi criada um pouco antes, em 1944.

${ }^{6}$ Intelectual chileno bastante atuante na CEPAL. 
resolver todo o problema do mundo. E o curso realmente foi ótimo, foi brilhante. Aí é que eu conheci o Celso [Furtado], que nos deu uma série de conferências [...]. (Oliveira, 1992, n.p.)

Esse curso era oferecido pela CEPAL e ministrado em conjunto com o BNDES; secundariamente, contava com a participação da CAPES (Coordenação de Aperfeiçoamento de Pessoal de Nível Superior), surgida em 1951, e do ISEB (Instituto Superior de Estudos Brasileiros), nascido em 1955. Francisco de Oliveira teve entre seus professores desse curso um destacado intelectual do ISEB, Roland Corbisier.

O ISEB era um dos grandes aparatos culturais de sustentação ideológica da política nacionalista e desenvolvimentista no período. (Pécaut, 1989; Toledo, 1977). A CAPES pertencia ao universo acadêmico-universitário nacional. Este pequeno exemplo de convivência entre estas duas instituições indica, ainda que preliminarmente, não ser impossível, na história de nossas ciências sociais, o diálogo e a articulação entre uma ciência explicitamente engajada - concretizada na trajetória do ISEB - e outra realizada em moldes acadêmicos típico-ideais - como era o caso da CAPES e do padrão universitário já então em pleno desenvolvimento no país. Raciocino, aqui, em alguma medida, em sentido diverso, ainda que não na direção contrária, aos estudos clássicos organizados por Sérgio Miceli a respeito da história das ciências sociais brasileiras, nos quais se estrutura uma sólida dualidade entre os dois tipos de produção científica/intelectual acima citados (Miceli, 1989).

Saindo do Banco do Nordeste, Francisco de Oliveira passa a trabalhar na iniciativa privada durante um certo tempo.

Aí fui embora para São Paulo pela primeira vez. Vim aqui convidado por um sujeito que tinha sido meu supervisor no Instituto Técnico de Estudos Econômicos [do Banco do Nordeste], em Fortaleza, o Diogo Gaspar. Era um gaúcho que tinha sido da FGV e do BNDES, e que tinha vindo para São Paulo convidado por uma empresa para ser diretor. Era a Lambretta, que fazia essas motonetas. Comecei então a ver o que é discriminacão contra o Nordeste. A indústria automobilística estava em pleno crescimento [...]. O merca- do de trabalho era uma loucura. Os operários entravam, treinando-se em três meses, e já saiam para outro emprego melhor, mais bem pago. A Lambretta era uma empresa 'porta de entrada' no mercado de trabalho. Eles passaram a atribuir isso ao fato de os nordestinos serem instáveis, insubordináveis. Queriam baixar uma ordem para não receber mais nordestinos como operários. (Oliveira, 1992, n.p.)

Francisco de Oliveira se insurge contra a possível decisão da empresa, argumentando, como ele mesmo relembra, com o próprio colega e antigo superior hierárquico que o recrutara para a Lambretta:

Eu disse: 'em primeiro lugar, se vocês adotarem isso, vão fechar. [...] Estou faz muito pouco tempo nisso, mas se eu aprendi direito o que vocês me ensinaram, os imigrantes estão sendo a nova mãode-obra, então são nordestinos e mineiros quem vêm para São Paulo. Se vocês obstarem nordestinos, vão simplesmente fechar! Então, antes que vocês fechem e eu perca meu emprego, vou-me embora como protesto a essa porcaria'. (Oliveira, 1992, n.p.)

Efetivamente foi o que fez, praticamente findando essa breve experiência na iniciativa privada. Esta atitude de Francisco de Oliveira remete a dois elementos significativos presentes na cultura política da época. Em primeiro lugar, sua firme apreensão das interpretações críticas relativas à modernização brasileira, realizada naqueles cursos ministrados por professores da CEPAL e do BNDES, organismos que comungavam - em maior ou menor medida - da cultura política de então, permeada de nacionalismo e desenvolvimentismo, e que, quase sempre, apostava nas potencialidades do "povo" brasileiro. Em segundo lugar, sua particular sensibilidade para com os trabalhadores (nordestinos inclusos), vivenciada a partir de sua posição social de técnico no Banco do Nordeste, engajado em questões regionais.

Com tal gesto, estava, também, desconstruindo um dos mitos caros aos primórdios da sociologia do trabalho efetivada no Brasil (e talvez em outras nações periféricas): a "inexperiência" do trabalhador como responsável pelas dificuldades enfrentadas nos processos de industrialização e modernização vividos por países não-centrais. 
Na verdade, mero preconceito social travestido de diagnóstico científico ou de constatação empírica.

\section{INSERÇÃO PROFISSIONAL E POLITICA NA SUDENE}

Pouco tempo depois, Francisco de Oliveira é informado que Celso Furtado estava montando uma equipe para uma grande iniciativa pública no Nordeste. Tratava-se da SUDENE.

[...] fui para o Rio conversar com o Celso, no BNDES. Ele tinha voltado da Inglaterra, tinha sido nomeado diretor regional do BNDES. Por certo que foi de Juscelino essa nomeação. Celso tomou o antigo grupo de trabalho que existia para o Nordeste [...]. Os dados já estavam levantados. O Celso, evidentemente, pegou, reordenou ao seu modo e deu aquela nova interpretação. [...] Eu pedi uma entrevista com ele, que me recebeu. ' $\mathrm{O}$ que queria?'. Eu disse que tinha sabido disso e que estava disposto a trabalhar. 'O que você faz?'. 'Eu faço isso e tal, fiz o curso da CEPAL, fui bem sucedido, tive notas tais e tais'. Não se comoveu, estava impassível. [...] Disse ele então: 'está bem, vai falar com José Medeiros'. Era o futuro chefe de pessoal, eu estava contratado! [...] Eu, besta, assim, nunca consegui emprego tão fácil. (Oliveira, 1992, n.p.)

E, assim, o pernambucano Francisco de Oliveira voltava para o Nordeste, após sua primeira e curta passagem por São Paulo.

Resolvi tudo, entreguei o negócio ao Diogo Gaspar, que já estava saindo da Lambretta também [...]. Eu tomei o ônibus ali na Av. Ipiranga, quase no cruzamento com a Av. São João, por isso entendo o Caetano Veloso. Quando o ônibus virou nem olhei para trás. Eu tinha uma raiva de São Paulo, tinha horror desta cidade, que é muito dura. Quem era de classe média como eu, em São Paulo, nos anos 50, amargava muito a vida porque você vivia numa solidão social enorme, talvez mais do que os 'proletas'. Eles puderam de alguma maneira reconstituir suas redes primárias. $\mathrm{Eu}$ não vim aqui para freqüentar a intelectualidade, estava em outro circuito, de empresa. Eu detestava essa cidade, com todas as forças do coração. (Oliveira, 1992, n.p.)

Voltando a morar em Recife, Francisco de Oliveira atua na SUDENE de 1959 a 1964, sendo uma de suas principais figuras até o golpe militar. Rapidamente é escolhido substituto eventual de Celso Furtado na direção da SUDENE.
Cheguei em março de 59 e em abril ocorreu o Seminário de Garanhuns, que instalou o Conselho de Desenvolvimento do Nordeste. Ali o movimento que fez a SUDENE mostrava-se explicitamente. Todas as forças sociais e as forças políticas que a criaram estavam presentes [....]. O código da aliança das forças que fizeram a SUDENE estava bem marcado: a grande burguesia industrial, passando pelas suas expressões regionais, Igreja, organizações camponesas, estudantado, intelectualidade, burocracia do Estado. De fora ficaram as oligarquias agrárias, os grandes latifundiários. [...] Aí iniciou-se um período muito fértil, muito rico.

[...] Aquilo era o olho do furacão.

[...] De fato, apesar disso, havia um processo de negociação política no Conselho da SUDENE, não era uma imposição. Havia ali uma nova experimentação, através desse planejamento o federalismo se renovava e se rearticulava de outro modo. Uma renovacão do conhecimento técnico e científico sobre o Nordeste. Todo isso foi deslanchado. [...]

Era uma equipe, na verdade, muito pequena. Quando iniciou-se tudo eram umas vinte pessoas, era um exército de Brancaleone. Depois houve um processo de recrutamento que seguiu um modelo Banco do Nordeste e BNDES. (Oliveira, 1992, n.p.)

Francisco de Oliveira não deixa de comentar, sucintamente, o significado social da SUDENE:

Evidentemente você desequilibrou a 'pax nordestina.' Está toda quebrada, por processos que vinham da industrialização do sul, na minha interpretação. Mas uma agência estatal que trabalhava no mesmo sentido que as forças cegas do processo de industrialização dava a essas forças uma certa conformação planejada, tomando o sentido mais progressista. Então o consenso se rompe, a velha estrutura de interesses não agüenta. Aquela estrutura de alianças [...] sofre uma fissura em que é visível que a burguesia regional passa à oposição [...]. (Oliveira, 1992, n.p.)

Pode-se considerar, nesse diapasão, que Francisco de Oliveira já era um dos principais quadros técnicos e formuladores da SUDENE e, portanto, do que costuma se chamar nacionaldesenvolvimentismo, tão proeminente na política brasileira do pré-64. Um período marcado pela grande confiança nas possibilidades de mudança propiciadas por uma ciência social engajada no desenvolvimento nacional. Sua convicção política e intelectual, a princípio, não é abalada nem com o advento do golpe militar. Em artigo datado de 1966, "Condições Institucionais do Pla- 
nejamento", persistia na perspectiva de uma construção teórica capaz de forjar o conhecimento sobre a sociedade brasileira bem como de, necessariamente, transformá-la. Daniel Pécaut, que menciona esse artigo, afirma com propriedade que Francisco de Oliveira então permanecia "fiel à crença na onipotência da razão esclarecida” (Pécaut, 1989, p. 226). ${ }^{7}$

Em 1964, vários quadros da SUDENE começam a sofrer a repressão do regime autoritário que se instaurara no país em 31 de março, atingindo sobremaneira a esquerda brasileira. Como relata Francisco de Oliveira:

Em 64 a repressão é seletiva e qualitativa. Eles tinham ficha de todo mundo. O consulado norteamericano tinha 16 vice-cônsules em Recife, depois do Rio era o maior consulado; evidentemente era um consulado com muitas tarefas administrativas porque ele geria muitas coisas, muito recursos da USAID, ${ }^{8}$ da Aliança para o Progresso, ${ }^{9}$ passava tudo por lá, evidentemente também muitas funções de inteligência [...], [portanto] já sabiam quem cooptar. (Oliveira, 1992, n.p.)

Vale a pena prosseguir com seu interessante relato daqueles dias:

Nós ficamos no Palácio de Governo com [o governador de Pernambuco Miguel] Arraes, tentando armar uma resistência [...]. Eu estava junto com o Celso [Furtado], [...] ele seria preso em qualquer ocasião porque é incapaz de fugir. Depois que nós saímos [...] do Palácio de Governo após a ordem de prisão ser dada para o Arraes, [...] a obrigação era apresentar-se ao Quartel General do $4^{\circ}$ Exército. Ali no meio do caminho do Palácio das Princesas, da Praça da República até o Hospício, há muitos becos no Recife por onde o carro poderia entrar e o Celso me perguntou: 'nós vamos até lá, Francisco?' E eu disse: 'eu por mim não ia'. Mas nós fomos porque eu estava no carro com ele. Pensei que realmente a gente não sairia de lá. Mas nós saímos. No gabinete do general Justino [Alves Bastos], na ante-sala, estava a aliança das forças do golpe: eram usineiros, grandes comerciantes do Recife, industriais da terra, todos formando ali uma espécie de corredor polonês por

${ }^{7}$ Referência do aludido artigo: OLIVEIRA, F. Condições Institucionais do Planejamento. Revista Civilização Brasileira, Rio de Janeiro, Civilização Brasileira, ${ }^{\circ} 5 / 6$, mar.1966.

${ }^{8}$ Sigla da United States Agency for International Development, muito atuante no Brasil na área de educação, especialmente após o golpe militar.

${ }^{9}$ Programa estadunidense de apoio ao desenvolvimento da América Latina, levado à frente durante toda a década de 60 para evitar a repetição da experiência revolucionária cubana pelas nações vizinhas. onde você passava, todos contentíssimos, não disfarçavam a satisfação. [...] Mas não houve nada, a mim nem dirigiu a palavra o general, eu era realmente nada.

Aí Celso lembrou a ele os deveres de um general do exército, que se insubordinou contra um presidente legitimamente eleito [...]. O general Justino disse que o Exército apreciava muito o trabalho do Celso à frente da SUDENE, que o trabalho dele iria continuar, que ficasse tranqüilo, que o Exército não tinha nada contra, absolutamente, eles estavam apenas dando um tempo para pôr as coisas em ordem. Fez aquele costumeiro discurso ao qual o Celso ouviu constrangido, mas sem comentários. Fomos em seguida para a SUDENE [...].

A situação ainda estava muito tensa por ali.

Cada um de nós tratou de arrumar suas coisas e preparar para entregar. Passamos esses dias todos assim. (Oliveira, 1992, n.p.)

No dia 06 de abril de 1964, ocorreu um jantar em homenagem a Celso Furtado, que, obviamente, estava saindo da SUDENE. Logo depois, Francisco de Oliveira é preso.

No dia seis [de abril] fomos para a casa de um amigo nosso, colega da diretoria [da SUDENE]. Jantamos, voltei para casa lá pelas onze horas da noite e fui dormir. Às três horas da manhã eles apareceram e me levaram numa daquelas antigas Rurais Willys. Eu fui espremido entre dois 'tiras' daqueles facinorosos da Polícia Civil de Pernambuco que eu já conhecia de outras alegacões. Na verdade, nas minhas experiências anteriores com 'o Estado detentor do monopólio legal da violência' (essa expressão tão anônima de Weber), eu nunca tinha sido torturado. Uns tapas, você leva, um empurrão, passa no xadrez só para aporrinhar... mas nunca tinha experimentado nada [de mais grave]. Mas a fama da Polícia Civil de Pernambuco era tenebrosa. Então, quando me vi naquela Rural entre dois monstros... eu realmente pensei que o fim tinha chegado... Mas não houve nada.

[...] Até que fui salvo pelos laços familiares que em 64 ainda valiam alguma coisa. Depois dos anos mais cruéis da repressão, esses laços não valiam muita coisa. Eu tinha um irmão que era da Polícia Militar e que passou-se para o lado do governo. [...] Foi minha sorte. Então fui levado para um quartel da Polícia Militar [...] onde fiquei mais dois meses. (Oliveira, 1992, n.p.)

Depois de solto, restou a Francisco de Oliveira voltar à SUDENE, onde, porém, restava marginalizado face à sua condição de alvo do regime autoritário.

[...] na SUDENE não me davam absolutamente nada para fazer. Todo mundo morria de vergonha, porque eu tinha tido um cargo importante, 
mas não só por isso, porque, sem demagogia, sempre me dei muito bem com todos os funcionários. Eu era um funcionário e todos sabiam que não tinha sido indicado para o posto por nenhuma razão política, nem mesmo pela esquerda, porque o processo, quando fui indicado, não teve absolutamente nada a ver com isso. (Oliveira, 1992, n.p.)

Tal situação, um tanto kafkiana, inicialmente foi enfrentada por Francisco de Oliveira de uma maneira até jocosa.

Chegava de manhã, me sentava numa cadeira frente a um burô e ficava o dia todo. Aí aproveitei para ler, né? Era coisa que eu não fazia há muito tempo, comecei a ler textos acadêmicos... estavam saindo algumas coisas boas, importantes no Brasil. Tinha aquele texto lindo do Fernando [Henrique Cardoso], a introdução do 'Capitalismo e Escravidão no Brasil Meridional'. ${ }^{10}$ Estava saindo aquele livro do Ossowski, 'Estrutura de Classes na Consciência Social'. ${ }^{11}$ [...] Comecei a ler uma literatura sociológica que fazia anos eu não freqüentava [...]. (Oliveira, 1992, n.p.)

Em seguida, porém, ele resolve mudar seu comportamento:

Mas eu percebi que aquilo era uma situação insustentável [...]. Os perseguidos políticos em Recife eram carimbados, eles viviam, como se dizia, com a mala pronta, a escova de dente e o pijama, quando tinham. Não quis ficar nessa situação, resolvi vir-me embora. Aproveitei ainda que, realmente, naquele momento e durante muito tempo ainda, a ditadura era muito desorganizada [...]. Eu não tinha muita coisa a preservar. Não quero passar a imagem de herói, eu não sofri tortura nenhuma, não fui herói; teve muita gente que enfrentou coisas muito piores do que eu, mas resolvi que não era o caso, não tinha porque ficar esperando um inquérito policial militar, não tinha porque me apegar a um cargo só porque era um posto vitalício. Já tinha chegado à conclusão de que o golpe era uma coisa pra valer, não era coisa de amadores e que uma certa fase, um certo tipo de engajamento, tinha acabado. (Oliveira, 1992, n.p.)

Francisco deOliveira percebiarapidamenteque o padrão de engajamento junto ao Estado, tão recorrente em intelectuais e técnicos naqueles anos de hegemonia nacionalista e desenvolvimentista na sociedade brasileira, estava interditado, e não por pouco tempo.

${ }^{10}$ Edição original: CARDOSO, F. H. Capitalismo e Escravidão no Brasil Meridional - o negro na sociedade escravocrata do Rio Grande do Sul. São Paulo: Difel, 1962.

${ }^{11}$ Edição original: OSSOWSKI, S. Estrutura de Classes na Consciência Social. Rio de Janeiro: Zahar, 1964.
Ele parte para o Rio de Janeiro, enquanto seu inquérito policial militar (IPM) tramitava.

Acho que no final das contas ter ido para o Rio foi melhor, mas por outro lado obrigou-me a viver numa espécie de clandestinidade sem ser clandestino, já que eu não podia ter emprego pois meu processo no Recife não estava concluído, o IPM era aquela coisa interminável.

No final do inquérito, ou quando chegavam a algumas conclusões sobre os principais responsáveis, decretavam uma série de prisões preventivas. Todo o primeiro escalão da SUDENE, uns quarenta ou cinqüenta com prisão preventiva decretada, eu estava no meio, com acusações de que eu tinha liderado a resistência... Fantasias que muito me orgulhariam se minha biografia incluísse isso [...]. Havia coisas do 'arco-da-velha': eu teria armado todos os carros da SUDENE com metralhadoras para resistir [...].

Tinha 30 anos. Até que consegui um 'habeas corpus' do Superior Tribunal Militar. Então veio um convite das Nações Unidas para ir a uma Missão na Guatemala. Nesse meio tempo eu tinha feito uma viagem para Santiago [...], porque tinha muita gente da SUDENE que foi para lá. Chegando, encontrei com Fernando Henrique [Cardoso], [Francisco] Weffort, todo esse pessoal, o Celso [Furtado]. [...] mas foi uma coisa, porque em Santiago não tinha vaga para ninguém mais, a cota de brasileiros tinha estourado, eles me ofereceram missão no Haiti ou na Bolívia [...]; voltei para o Brasil. Realmente foi uma loucura essa época. Fui à Guatemala, passei um ano lá. Era uma Missão de seis anos mas não gostei nada da vida de consultor internacional. Com um ano cortei o contrato e fui para o México para um programa do BID, voltado para treinamento em desenvolvimento econômico. ${ }^{12}[. .$.$] Fiquei três$ anos no exterior entre essas duas instituições. Voltei, então, ao Brasil.

[...] em fim de 68... Aí tentei ir para o Nordeste de novo. (Oliveira, 1992, n.p.)

Mas essa tentativa foi frustrada. Ele recebe, a seguir, um convite para retornar a São Paulo, para trabalhar numa consultoria privada, onde ficou cerca de dois anos, mesmo contra seu desejo inicial: “[...] nunca esperava voltar a essa cidade para ficar; e fiquei, estou aqui, virei paulistano... contra vontade... uma história nada exemplar.” (Oliveira, 1992, n.p.)

\footnotetext{
${ }^{12}$ Banco Interamericano de Desenvolvimento, criado em 1959 pela OEA, Organização dos Estados Americanos, mas dela independente atualmente. No BID, Francisco de Oliveira atuou no Centro de Estudios Monetários Latinoamericanos (CEMLA).
} 


\section{TEMPOS DE CEBRAP}

Francisco de Oliveira se radica em São Paulo porque passa a atuar, a partir de 1970, no CEBRAP - Centro Brasileiro de Análise e Planejamento, organismo intelectual não-governamental. O CEBRAP era formado, majoritariamente, por professores da USP - alguns já de renome cassados pelo regime.

O Fernando Henrique [Cardoso] me convidou. Foi o meu desastre. Convidou-me para participar de um projeto no CEBRAP sobre planejamento nacional que tinha uma parte sobre planejamento regional. Era isso que eles queriam que eu fizesse.

[...] Fui ficando até um dia em que eles me adotaram. [...] Acho que, realmente, os períodos da SUDENE e do CEBRAP são as minhas duas formações mais importantes. E, do ponto de vista do que faço hoje, o CEBRAP é onde eu me forjei. (Oliveira, 1992, n.p.)

Para muitos estudiosos do pensamento social e político brasileiro, desenvolvido no pós-64, o CEBRAP pode ser visto como diametralmente oposto aos aparatos intelectuais e políticos predominantes no período de hegemonia nacionaldesenvolvimentista em nossa sociedade. (Pécaut, 1989; Sorj, 2001; Lahuerta, 2001). Diferentemente destes, como o ISEB especialmente, mas, também, a SUDENE, onde a atuação pública de intelectuais e técnicos vinha amalgamada ao Estado, no CEBRAP (e em outros organismos intelectuais engajados como o Centro de Estudos de Cultura Contemporânea - CEDEC e o Centro Ecumênico de Documentação e Informação CEDI, por exemplo) essa atuação era realizada nos marcos da sociedade civil, categoria então emergente na esquerda brasileira e extensamente adotada a partir da instalação da ditadura militar. ${ }^{13}$

Bernardo Sorj (2001, p. 36), a respeito, afirma que a "[...] experiência universitária e profissional de Francisco de Oliveira já era outra [da dos seus colegas cebrapianos]”. (Sorj (200, p. 22),

${ }^{13}$ Sobre o CEDEC e o CEDI, bem como sobre outros organismos intelectuais engajados, principalmente, em movimentos populares, que caracterizaram a sociedade civil brasileira no pós-64 de modo tão significativo quanto o CEBRAP veja-se: PERRUSO, 2009 além disso, observa: "Praticamente todos os membros não-uspianos do CEBRAP, com exceção de Francisco de Oliveira, passaram pela FLACSO (Faculdade Latino-Americana de Ciências Sociais) ${ }^{14}$ e/ou pela CEPAL, ambas sediadas em Santiago." Francisco de Oliveira, todavia, cedo tinha efetivado amplo contato com o pensamento cepalino, como já visto, mesmo não tendo ficado na capital chilena.

É certo que a filiação do CEBRAP a uma tradição paulista e uspiana de produção intelectual realizada em moldes acadêmicos é inegável. Contudo, estavam esses intelectuais universitários em acelerado processo de aprofundamento no que tange a um engajamento político, processo que vinha, é bom que se ressalte, de antes do golpe militar. Ademais, Sorj (2001, p. 90) aponta, com grande pertinência, que Francisco de Oliveira, "[...] misto de visionário-poeta e sociólogo marxista, trazia a problemática regional e nordestina a um grupo de intelectuais que tendiam a ver o Brasil sob um ângulo paulista.” Assim, ele se inseria no CEBRAP de modo diferenciado.

Eles foram muito abertos, porque eu não tinha pós-graduação nenhuma nem tradição acadêmica alguma. O Fernando [Henrique Cardoso] tinha muita abertura, uma percepção para além dos padrões da Academia. (...) O [Cẩndido] Procópio [Ferreira de Camargo], o Juarez [Brandão Lopes], o [Paul] Singer, o [José Arthur] Giannotti, a Elza [Berquó], o Octavio [Ianni]... Havia uma conjunção de coisas que, acho, me fizeram muito bem. Essa abertura, essa desburocratização, entendo que eu dificilmente teria vivido num outro lugar. Primeiro, ver o que você tem a dizer, para depois te cobrar desde o ponto de vista formal. Uma coisa que eu acho que já se inverteu, agora é uma coisa muito formalista. O Giannotti, ${ }^{15}$ sobretudo, está num formalismo, numa chatice... Mas eles tinham muito de audácia e eu acho que se não fosse isso eu não teria tido a chance que tive.

(...) Mas acho que também dei muito, sem exagerar, a esse processo de construcão do CEBRAP, a essa identidade que o CEBRAP logrou. (...) Talvez, precisamente pelas características que eu agreguei ao grupo. Como eu não tinha exatamente uma identidade muito forte com qualquer das disciplinas de forma muito acabada, eu tinha um trânsito mais fácil, até mesmo por uma forma-

${ }^{14}$ A FLACSO foi criada pela UNESCO e por governos latino-americanos em 1957.

${ }^{15} \mathrm{Na}$ época da entrevista realizada com Francisco de Oliveira, 1992, o filósofo José Arthur Giannotti era coordenador do CEBRAP, cargo que exerceu de 1986 a 1998. 
ção que não era satisfatória, eu tinha mais possibilidade de ousar; eu usei essa ignorância para ousar. Se tivesse uma melhor formação talvez eu não ousasse. Então, houve uma relação, diria, dialética, entre essa chance de ousar e a receptividade que o CEBRAP teve naquela conjuntura. [...] E, também, fui para o plano da discussão pública, desde logo me juntei ao Fernando Henrique na discussão política [...]. Fui para os jornais, ajudei a formar uns jornais alternativos.. o Opinião, o Movimento. ${ }^{16}$ (Oliveira, 1992, n.p.)

Além disso, ele participa com destaque, junto a cebrapianos e outros intelectuais brasileiros, de atividades da Sociedade Brasileira para o Progresso da Ciência (SBPC), entidade também muito importante em nossa reconstrução democrática, notadamente no que tange às camadas universitárias então em expansão no país. ${ }^{17} \mathrm{E}$ em 1974, já figura importante no CEBRAP, é preso novamente, por curto período. (Sorj, 2001)

Francisco de Oliveira, percebe-se, analisa com sagacidade sua própria inserção em um processo importante por que passava a sociedade brasileira em suas relações com nossa intelectualidade, a partir de fins dos anos 1960. No campo da esquerda e da oposição ao regime militar, a politização e o engajamento de "novos" intelectuais de estirpe acadêmica (Fernando Henrique Cardoso, Octavio Ianni, Paul Singer e outros) eram incrementados por alguns poucos intelectuais anteriormente dedicados à investigação eà transformação-sempre conjugadas - da sociedadebrasileira, caso deFrancisco de Oliveira. Aomesmo tempo, esses "velhos" intelectuais, forjados no período nacional-desenvolvimentista, somavam à sua formação mais "generalista" - tão típica do ISEB, por exemplo - um treinamento intelectual de padrão universitário, "formal". Creio que tal característica da trajetória de Francisco de Oliveira constitui uma exceção diante de outros intelectuais atuantes desde o período anterior ao golpe de 64. Por outro lado, analisando sua trajetória, é possível relativizar, em alguma medida, as distâncias de estilo

${ }^{16}$ Os jornais Opinião e Movimento foram dois dos principais veículos alternativos à grande imprensa nos anos da ditadura militar. O primeiro circulou de 1972 a 1978, o segundo de 75 a 81 .

17 Francisco de Oliveira atuou também em movimentos associativos: foi presidente da Associação dos Sociólogos do Estado de São Paulo (ASESP) de 1979 a 1982 intelectual e político entre as gerações atuantes no pré e no pós-64, entre nacionalistas e desenvolvimentistas, por um lado, e seus críticos, por outro (Perruso, 2009, p. 45). ${ }^{18}$ Estas distâncias não deixam de ser homólogas à antes exposta separação opositiva, proposta por Miceli, entre uma ciência engajada, fomentada via Estado, e uma ciência universitária - contudo, já inclinada a uma politização que apostava nas potencialidades e virtudes da sociedade civil.

O CEBRAP passa a ser parte importante da reconstrução de políticas democráticas e de esquerda no Brasil dos anos 1970, notadamente do ponto de vista intelectual. Posteriormente, do CEBRAP saem estudiosos como Bolívar Lamounier, que participará da criação do Instituto de Estudos Econômicos, Sociais e Políticos de São Paulo (IDESP) em 1979, cujo foco maior éa reconstrução da institucionalidade democrático-representativa brasileira. Saem, também, pesquisadores dedicados a investigar, de modo engajado, a reativação do movimento operário e dos movimentos sociais em geral, como Francisco Weffort eLúcio Kowarick (entre outros), criando o antes citado CEDEC em 1976.

Anteriormente a essas dissensões, os debates internos realizados no CEBRAP, os chamados "mesões", constituíram o ambiente onde se produziram e se discutiram textos clássicos sobre a realidade social brasileira do período, tais como: "Além da Estagnação" de José Serra e Maria da Conceição Tavares (de 1971, publicado em 1972) e "O Regime Político Brasileiro" (publicado em 1972) de Fernando Henrique Cardoso. Motivados por estes trabalhos, Francisco de Oliveira produz "Crítica da Razão Dualista” em 1972 e Paul Singer escreve "As Contradições do Milagre" em 1973 (Sorj, 2001, p. 54$).^{19}$

${ }^{18}$ José Sérgio Leite Lopes, comentando o presente trabalho, aponta, com muita propriedade, que o perfi "planejador" de Francisco de Oliveira agregava justamente o que faltava à maioria dos membros do CEBRAP, egressos de universidades: a experiência em ciências sociais aplicadas.

${ }^{9}$ Referências das obras: Serra, J.; Tavares, M. C. Além da Estagnação: uma discussão sobre o estilo de desenvolvimento recente do Brasil. El Trimestre Economico, Ciudad de México, nº 152, nov./dez. 1971; Cardoso, F. H. O Regime Político Brasileiro. Estudos CEBRAP, São Paulo, CEBRAP, $\mathrm{n}^{\circ}$ 2, out./dez. 1972; Oliveira, F. A Economia 
Sobre a "Crítica da Razão Dualista”, Sorj (2001, p. 55) aponta: "O texto de Francisco de Oliveira, em particular, conhecerá nos anos 70 um impacto impressionante, sendo durante toda a década leitura obrigatória nos cursos de ciências sociais.” E, da mesma maneira, Daniel Pécaut (1989, p. 284) afirma: "[...] poucos textos terão uma repercussão tão grande [...]. Divulgado como texto básico na maioria das universidades, discutido e utilizado em muitos artigos [...]."

Sorj (2001) e Pécaut (1989), analisando o contexto intelectual e político brasileiro nos anos 1970, julgam de maneira similar o significado dessa obra de Francisco de Oliveira. Sorj (2001, p. 55) assim diagnostica:

Embora o trabalho possua méritos e enorme criatividade, sua tendência a invocar o processo de acumulação como 'categoria totalizante' [...] de alguma forma facilitou o caminho para que setores da nova geração de cientistas sociais simplificassem sua visão da sociedade brasileira, caindo muitas vezes num funcionalismo marxista incapaz de compreender as especificidades e complexidades da textura da sociedade e do capitalismo brasileiros. ${ }^{20}$

Por seu turno, Pécaut (1989, p. 284) qualifica a "Crítica da Razão Dualista” como economicista e hiperfuncionalista, o que resultaria na dissolução dos atores sociais e da política em geral. Ainda assim, o texto seria "singularmente brilhante e rico em hipóteses".

Enquanto Sorj (2001) conclui que a disseminação dessa obra se deve à facilidade com que seu marxismo precipitava uma explicação reducionista de grande escopo sobre a sociedade brasileira, Pécaut (1989, p. 284/286) fornece outras razões além dessa. Entendia este que tal tipo de marxismo implicava uma reflexão, não apenas totalizante, mas, também, pessimista, consubstanciando uma "cultura da recusa" - a qual era comungada por muitos intelectuais de esquerda durante a ditadura mili-

Brasileira: crítica à razão dualista. Estudos CEBRAP, São Paulo, CEBRAP, nº 2, out./dez. 1972; e Singer, P. As Contradições do Milagre. Estudos CEBRAP, São Paulo, CEBRAP, n 6 , out./dez. 1973.

${ }^{20}$ Sorj elenca outras questões atinentes à referida obra de Francisco de Oliveira, que, contudo, não cabem no âmbito deste artigo. tar: "Se essas teorizações têm tanto sucesso, apesar do reconhecimento da impotência que abrigam, é porque constituem uma via para expressar uma oposição política global.” Pécaut (1989) citava outros autores do período que, assim como Francisco de Oliveira, produziriam diagnósticos dotados de grande inflexibilidade teórica e analítica, capazes, todavia, de apontar para uma oposição totalizante à modernização conservadora levada a cabo pela ditadura militar: os já citados Paul Singer e Lúcio Kowarick. ${ }^{21}$

Mas, em que consiste, essencialmente, a "Crítica da Razão Dualista”, para ser motivo das reservas de Pécaut quanto aos seus méritos e as de Sorj quanto aos perigos de uma leitura superficial sua? Segundo Leonardo Gomes Mello e Silva (em resenha à reedição da "Crítica da Razão Dualista”), acertando contas com o pensamento cepalino - no qual, em parte, se formou intelectualmente - e com as teorias da dependência então em voga

Francisco de Oliveira terminou por acertar o passo de nossa dialética da entrada na modernidade capitalista, cuja marca, explicitada já no primeiro capítulo do ensaio, pode ser descrita como sendo o 'uso' que o setor moderno da economia faz do setor 'atrasado', cravando uma unidade contraditória, mas funcionalmente operante, contra a interpretação dominante que via antagonismo e incompatibilidade entre os dois setores ou 'pólos'. (Oliveira, 2005, p. 177) ${ }^{22}$

A inovadora perspectiva lançada por essa obra poderia se desdobrar em muitos campos da investigação e da reflexão sociológica e intelectual: como a economia capitalista contemporânea se desenvolvia de maneiras diferentes das imaginadas a partir da experiência "clássica" europeia; como se efetivavam os conflitos entre as classes sociais, agora não mais sob um prisma evolucionista ou desenvolvimentista; como a ques-

${ }^{21}$ Ver, respectivamente, Singer, P. As Contradições do Milagre. Estudos CEBRAP, São Paulo, CEBRAP, nº 6, out./ dez. 1973; e Kowarick, L. Capitalismo e Marginalidade na América Latina. Rio de Janeiro: Paz e Terra, 1975.

${ }^{22}$ Fazendo referência ao legado intelectual de Celso Furtado, Francisco de Oliveira indica a permanência de "um certo dualismo na interpretação furtadiana”, o que não impediu que elaborasse "uma interpretação singular, notável”. (Oliveira, Coutinho \& Comparato, 2001, p. 91) 
tão do trabalho era impactada pela superexploração e pela informalidade correspondente; como cultura e arte interagiam com esse amálgama - contraditório mas real - entre "atraso" e modernidade. ${ }^{23}$

Luiz Antonio Machado da Silva (2003) também assinala a importância dessa obra de Francisco de Oliveira, especificamente no que tange à questão do trabalho informal, acrescentando, todavia, um tom crítico, também relacionado ao economicismo que nela estaria presente:

[...] compartilhava-se a idéia de que o modelo extraído do trabalho industrial assalariado tendia a se universalizar como forma de produção de riqueza e, ao mesmo tempo, como meio de reprodução social. [...] o que é o mesmo que dizer que as formas não-mercantis de trabalho e consumo eram vistas como remanescentes de outros períodos históricos e explicadas, segundo a perspectiva adotada, como conseqüências do ‘subdesenvolvimento', da 'dependência' ou do 'capitalismo periférico'. [...] Que eu saiba, a única exceção foi o trabalho já citado de Oliveira (1972), mas mesmo nesse texto permanece a ênfase na esfera econômica [...]. (Silva, 2003, p. 148)

Talvez, o que seja incômodo nessa inovação teórica de Francisco de Oliveira - e nisso, creio, reside um dos maiores méritos da "Crítica da Razão Dualista" - consista na revelação de que democracia e capitalismo, na contemporaneidade, caminham entrelaçados a autoritarismo e patrimonialismo. É o rompimento de tal dualismo que Pécaut (1989) e Sorj (2001) consideram inaceitável, uma vez que a preocupação prioritária de ambos os autores com o aperfeiçoamento de nossa institucionalidade democrático-representativa num contexto capitalista - referentes modelares da modernidade - aponta, também, para uma perspectiva dualista, na qual "atraso" seria acompanhado de estatismo, corporativismo, revolucionarismo e outros "ismos" de conotação pejorativa para quem os utiliza. Isto é, as posições liberais de Pécaut (1989) e Sorj (2001) - absolutamente sólidas, ressalte-se - são infensas à inovado-

${ }^{23}$ Já no início do atual século, Francisco de Oliveira ressalta a pertinência de uma perspectiva analítica antidualista: "O difícil é pensar agora essa trama de um capitalismo globalizado que torna funcional, pro domo suo, as práticas que numa perspectiva tipo "capitalismo e ética protestante" pareciam ser disfuncionais." (Oliveira, Coutinho \& Comparato, 2001, p. 93). ra interpretação marxista desenvolvida por Francisco de Oliveira nesta sua obra capital.

Este, por sua vez, era, e é, extremamente crítico ao marxismo pecebista predominante no pré$64 .{ }^{24}$ Segundo a antes mencionada resenha de Leonardo Gomes Mello e Silva (2005), Francisco de Oliveira nega, peremptoriamente, "uma suposta clareza que oporia burguesia nacional e setores agrário-exportadores, ou, mais contemporaneamente, capital financeiro e capital produtivo"; e também critica o pensamento político e social nacionaldesenvolvimentista, do qual o PCB se aproximara antes do golpe, o que é visível quando ele constata que nossa "força de trabalho assalariada industrial" fora "forjada sob o predomínio do populismo". (Oliveira, 2005, p. 177 e 178, respectivamente).É certo que, aqui, Francisco de Oliveira vai se distanciando de sua própria formação original. Mas com ela não rompe completamente. Não se trata, portanto, de um "novo convertido", tipo que nega todo seu passado sem compreender que nele, de alguma maneira, também estão as raízes das posições assumidas no presente.

Ademais, Francisco de Oliveira mantém características da produção intelectual do pré-64, mesmo depois de estabilizada sua vida em São Paulo, no CEBRAP e, posteriormente, na USP, onde, a partir de fins dos anos 1980, será professor. Leonardo Gomes Mello e Silva (2006, p. 62) observa que suas obras são confeccionadas na forma-ensaio, o que, ressalto, era recorrente na intelectualidade nacionalista e desenvolvimentista em geral e isebiana em particular. Trata-se de escrita distinta do estilo monográfico comum aos intelectuais universitários. Francisco de Oliveira sempre se manteve crítico da extrema compartimentação do pensamento em disciplinas científicas, da "falsa autarquia", do "isolamento das grandes correntes das ciências humanas e sociais". (Oliveira, Coutinho \& Comparato, 2001, p. 89).

${ }^{24}$ Elencando alguns autores referenciais na história do pensamento social e político brasileiro, Francisco de Oliveira aponta a centralidade e a originalidade de Caio Prado Jr., ainda que a partir de um "terreno mais ou menos infértil do ponto de vista do partido teórico que toma, ancorandose no marxismo, numa cultura que não havia produzido até então nada muito inovador na utilização do ferramenta marxista”. (Oliveira, Coutinho \& Comparato, 2001, p. 90) 
Sob esse mesmo prima, podemos observar outra situação em que, na sua trajetória, permanências e mudanças estão em estreito contato como que a negar, na prática, o dualismo por ele repudiado teórica e analiticamente. Após escrever a "Crítica da Razão Dualista”, Francisco de Oliveira produz no CEBRAP uma obra que se volta para o que viveu no pré-64: "Elegia para uma Re(li)gião Sudene, Nordeste. Planejamento e Conflito de Classes" (1977), que foi dedicada, entre outros, "aos trabalhadores, operários e camponeses do Nordeste", à “Miguel Arraes de Alencar, Francisco Julião e Mário Magalhães da Silveira". ${ }^{25}$

Em “Elegia para uma Re(li)gião”, ele visualiza, de modo menos cientificista e iluminista, a temática do planejamento:

O padrão ‘planejado' não é, desse ponto de vista, senão uma forma transformada do conflito social, e sua adoção pelo Estado em seu relacionamento com a sociedade é, antes de tudo, um indicador do grau de tensão daquele conflito, envolvendo as diversas forças e os diversos agentes econômicos, sociais e políticos. O planejamento não é encarado, portanto, apenas como uma técnica de alocação de recursos, em qualquer nível, nem como uma panacéia [...]. (Oliveira, 1977, p. 23)

Já não se trata tanto de uma "crença na onipotência da razão esclarecida", para usar os termos de Pécaut, antes vistos. Sua sociologia e suas interpretações sobre as relações entre trabalho e capital no Brasil fundam-se, cada vez mais, no conflito. Francisco de Oliveira também demarca sua distância para com "uma classe de marxismo vulgar":

A história política e social do Brasil foi exageradamente 'homogeneizada', uniformizada, do ponto de vista teórico, da chamada 'interpretaçẫo' do Brasil, para além do que a própria tendência de homogeneização da reprodução do capital em escala nacional conduzia. (Oliveira, 1977, p. 70 - marca do autor).

Sua abordagem, a partir do conflito de classe entre capital e trabalho, se desenvolve, nesta obra, em oposição aos padrões estabelecidos pelo pensa-

${ }^{25}$ Francisco Julião foi líder das Ligas Camponesas, muito fortes no Nordeste no pré-64. Mário Magalhães da Silveira foi um importante sanitarista, atuante na mesma conjuntura. mento social e político nacional-desenvolvimentista, no qual se socializara intelectualmente, fazendo com que observe a oposição direta proletariadoburguesia, que o PCB ainda secundarizava por conta da aposta numa "burguesia nacional”: “[...] no Nordeste açucareiro-têxtil, a oposição proletariado-burguesia sempre foi muito clara." (Oliveira, 1977, p. 79). Isto permite, também, que perceba as clivagens de classe e a força de outros atores sociais de extração popular antes de 1964:

É nesse contexto, e exatamente nessas zonas, que a pax agrariae nordestina entra em colapso, e esse semi-campesinato aparece como ator político por excelência, sob a égide das Ligas Camponesas de Francisco Julião. (Oliveira, 1977, p. 81)

Em fins dos anos 1970, a transição democrática brasileira se iniciava. Os intelectuais cebrapianos, partícipes desse processo protagonizado pela sociedade civil brasileira e por seus movimentos populares, se dividem entre a inserção no já existente MDB (Movimento Democrático Brasileiro, depois PMDB) - à frente Fernando Henrique Cardoso (nele atuante desde a primeira metade da década) e Bolívar Lamounier - e a fundação do PT (Partido dos Trabalhadores) - da qual participaram Francisco de Oliveira, Paul Singer, Francisco Weffort, José Álvaro Moisés, Vinícius Caldeira Brant, entre outros, alguns deles já no CEDEC. Cerca de uma década após, em 1988, Francisco de Oliveira passa a ser Professor Titular no Departamento de Sociologia da USP.

Em todo esse período, continua desenvolvendo suas reflexões e investigações envolvendo as relações entre trabalho e capital, o desenvolvimento das classes, conflitos sociais e cidadania. Na segunda metade dos anos 80, elabora um trabalho sobre o movimento sindical dos petroleiros da Bahia (Oliveira, 1987), no qual analisa as dificuldades da formação de uma consciência classista numa empresa estatal-a Petrobrás - onde a marca do nacionalismo e do desenvolvimentismo era - e ainda é - muito forte. Suas conclusões foram objeto de debates e questionamentos na sociologia do trabalho brasileira. (Guimarães et al., 1995; Neves, 2007). Novamente as tensões entre 
nacionalismo - privilegiado na reflexão isebiana e classismo - temática emergente na esquerda brasileira pós-golpe, desde então bastante presente nas universidades - perpassam sua sociologia, ao mesmo tempo que contextualizam sua dissonante trajetória intelectual e política.

\section{À GUISA DE CONCLUSÃO}

Francisco de Oliveira por vezes participou da conformação de vagas democratizantes em nosso país, que ajudaram a minorar nossa histórica e estrutural desigualdade social. Em outras ocasiões, não hesitou em remar contra a corrente, como, por exemplo, na década de 1990, que viu a ascensão, no Brasil, do neoliberalismo, “[...] essa teoria convencional que tornou-se pensamento único no mundo”. (Oliveira, Coutinho \& Comparato, 2001, p. 95) Como sintetiza, com grande perspicácia, Marilena Chauí a respeito de sua obra:

A cada instante em que se consolidou uma explicação sobre o Brasil - uma explicação histórica, sociológica e econômica - nós sempre pudemos contar com o seu trabalho para a desmontagem, para a explicação e uma outra compreensão. Não uma outra compreensão qualquer, uma compreensão materialista, mas séria. (Chauí, 2006, p. 25)

Neste sentido, uma possível biografia sua de maneira alguma evoca um "deslocamento linear, unidirecional” ou "[...] um todo, um conjunto coerente e orientado, que pode e deve ser apreendido como expressão unitária de uma 'intenção’ subjetiva e objetiva [...]” - isto é, a “ilusão biográfica” tão bem definida por Bourdieu (1996, p. 184). Pelo contrário, aponta, justamente, para a “[...] noção de trajetória como uma série de posições sucessivamente ocupadas por um mesmo agente [...] em um espaço ele próprio em devir e submetido a transformações incessantes”(Bourdieu, 1996, p. 189 -itálicos do autor). ${ }^{26}$

${ }^{26}$ A respeito, veja-se, ainda: WINKIN, 2004.
O fato de Francisco de Oliveira ter sido figura destacada da cultura política nacionalista e desenvolvimentista do pré-64 - na SUDENE - e de uma cultura política crítica deste legado após o golpe - no CEBRAP - consubstancia uma trajetória dissonante, movimentada, por vezes turbulenta. E evidencia o “devir” do espaço social em que atuava, propiciando uma relativização da dualidade institucional, estilística e ideológica entre estes dois verdadeiros tipos ideais de produção e atuação intelectual, estabelecidos por Miceli (1989). Embora tal dualidade tenha até se efetivado na experiência de muitos dos que protagonizaram o período que trouxe a substituição de um padrão intelectual e político hegemônico (o ensaísmo engajado à maneira isebiana) por outro (os universitários politizados de origem uspiana), talvez ela não seja tão necessariamente opositiva como estamos acostumados a ler na história de nosso campo intelectual e da institucionalidade das ciências sociais brasileiras. O trânsito de Francisco de Oliveira por ambos os padrões não deixa de revelar, por baixo de diferentes caminhos de engajamento intelectual, um permanente anseio por mudança numa sociedade tão marcada pela desigualdade como a brasileira.

Recebido para publicação em 24 de agosto de 2011 Aceito em 28 de maio de 2012

\section{REFERÊNCIAS}

BOURDIEU, Pierre. A ilusão biográfica. In: FERREIRA, M. M. ;AMADO, J. (Orgs.) Usos e abusos da história oral. Rio de Janeiro: FGV, 1996. p. 183-191.

CHAUÍ, Marilena. Radicalidade da crítica. In: RIZEK, C. S.; ROMÂO, W. M. (Orgs.) Francisco de Oliveira: a tarefa da crítica. Belo Horizonte: UFMG, 2006. p. 25-28.

GOMES, A. C. A invenção do trabalhismo. São Paulo: Vértice/IUPERJ, 1988.

GUIMARÃES, A. S. et al. Imagens e identidades do trabaIho. São Paulo: HUCITEC/ORSTOM, 1995.

LAHUERTA, M. Intelectuais e resistência democrática: vida acadêmica, marxismo e política no Brasil. Cadernos $A E L$, Campinas, IFCH/UNICAMP, $\mathrm{n}^{\circ}$ 14/15, p. 56-94, 2001.

LOPES, J. S. L. Precursores da sociologia do trabalho no Brasil: Aziz Simão, Evaristo de Moraes Filho, José Albertino Rodrigues, Juarez Brandão Lopes e Leôncio Martins Rodrigues. Rio de Janeiro: Mimeo, 2004. 
MICELI, S. História das Ciências Sociais no Brasil. v. 1. São Paulo: IDESP/Vértice/FINEP, 1989.

NEVES, Paulo Sérgio da Costa. Sindicalismo, populismo e nacionalismo: os sindicatos dos trabalhadores da indústria petrolífera na Bahia, Brasil, entre 1960 e 1990. In ACTAS DEL V CONGRESO LATINOAMERICANO DE SOCIOLOGIA DEL TRABAJO. Montevideo. Montevideo: ALAST, 2007.

OLIVEIRA, F. Crítica à razão dualista/O Ornitorrinco. São Paulo: Boitempo, 2003. Resenha de: SILVA, L. G. M. Dois Clássicos em Um. Revista Brasileira de Ciências Sociais. São Paulo, ANPOCS, n ${ }^{\circ}$ 57, vol. 20, p. 177-180, fev. 2005.

A economia da dependência imperfeita. Rio de Janeiro: Graal, 1977.

A economia brasileira: crítica à razão dualista. Estudos CEBRAP, São Paulo, CEBRAP, no 2, p. 3-82, out./ dez. 1972 .

Elegia para uma Re(li)gião - SUDENE, Nordeste. Planejamento e conflito de classes. Rio de Janeiro: Paz e Terra, 1977.

O elo perdido: classe e identidade de classe. São Paulo: Brasiliense, 1987.

Entrevista. [set. 1992]. Entrevistador: José Sérgio Leite Lopes. São Paulo: 1992. 01 cassete sonoro.

OLIVEIRA, F; COUTINHO, C. N. ;COMPARATO, F. K. Como Pensar? Lua Nova. São Paulo, CEDEC, $n^{\circ} 4$, p. 87132, set./dez. 2001
PÉCAUT, D. Os intelectuais e a política no Brasil - entre o povo e a nação. São Paulo: Ática, 1989.

PERRUSO, M. A. Em busca do "Novo": intelectuais brasileiros e movimentos populares nos anos 1970-80. São Paulo: Annablume, 2009.

SILVA, Leonardo Gomes Mello. Chico de Oliveira, Sociólogo. In: RIZEK, C. S.; ROMÃO, W. M. (Orgs.) Francisco de Oliveira: a tarefa da crítica. Belo Horizonte: UFMG, 2006. p. 55-70.

SILVA, Luiz Antonio Machado da. Mercado de trabalho, ontem e hoje: informalidade e empregabilidade como categorias de entendimento. In: SANTANA, M. A.; RAMALHO, J. R. (Orgs.) Além da fábrica - trabalhadores, sindicatos e a nova questão social. São Paulo: Boitempo, 2003. p. 140178.

SORJ, B. A construção intelectual do Brasil contemporâneo - da resistência à ditadura ao governo FHC. Rio de Janeiro: Jorge Zahar, 2001.

TOLEDO, C. N. ISEB: fábrica de ideologias. São Paulo: Ática, 1977.

WEBER, M. A ‘Objetividade' do conhecimento nas ciências sociais. In: Weber - Coleção Grandes Cientistas Sociais. São Paulo: Ática, 1999, p. 79-127.

WINKIN, Yves. Erving Goffman: o que é uma vida? O incômodo fazer de uma biografia intelectual. In: GASTALDO, E. (Org.). Erving Goffman: desbravador do cotidiano. Porto Alegre: Tomo, 2004. p. 13-36. 


\section{A DISSONANT TRAJECTORY: Francisco de Olivei- ra, SUDENE and CEBRAP}

\author{
Marco Antonio Perruso
}

This article presents one of Brazil's most important social scientists, Francisco Maria Cavalcanti de Oliveira, better known as Chico de Oliveira. The fact that he was an important figure in pre-1964 nationalistic and pro-development political culture - in SUDENE - and in the post-coup political culture critical of this legacy - in CEBRAP - constitutes a trajectory of dissonance, activeness and sometimes turbulence. It also reflects the devir (kinesis) of the social space in which he was an actor, triggering a relativization of an institutional, stylistic and ideological duality between these two true ideal types of production and intellectual activity. Although this duality has made all the difference for many of those who protagonized the period which brought the substitution of an intellectual standard and political hegemony (essayism engaged in the ISEB manner) for another (politicized university students of USP origin), perhaps because it is not necessarily so oppositional as we usually read in the history of our intellectual field and of the institutionalization of Brazilian social sciences.

Key Words: Brazilian Social Thought. Intellectuals. Political Culture. Francisco de Oliveira.

\section{UNE TRAJECTOIRE DISSONANTE: Francisco de Oliveira, la SUDENE et le CEBRAP}

\author{
Marco Antonio Perruso
}

Cet article présente l'un des plus importants scientifiques du monde des sciences sociales brésiliennes, Francisco Maria Cavalcanti de Oliveira, plutôt connu comme Chico de Oliveira. Le fait d'avoir été une figure de proue de la culture politique nationaliste et pour le développement d'avant $64-$ dans la SUDENE - et de la culture politique critique de cet héritage après le coup d'état - dans le CEBRAP - constitue une trajectoire dissonante, mouvementée, quelques fois turbulente. Le "devenir" de l'espace social dans lequel il agissait est mis en évidence et permet une relativisation du dualisme institutionnel, stylistique et idéologique entre ces deux véritables types idéaux de production et d'action intellectuelle. Bien qu'une telle dualité ait fait toute la différence pour beaucoup de ceux qui étaient en tête d'affiche à l'époque et qui a substitué un modèle intellectuel et politique hégémonique (celui d'un essai engagé à la manière de l'Institut Supérieur d'Etudes Brésiliennes) à un autre (celui des universitaires politisés issus de l'Université de Sao Paulo). Elle n'est peut-être pas aussi nécessairement oppositive que ce à quoi nous sommes habitués en lisant l'histoire de notre champ intellectuel et quant à l'institutionnalisation des sciences sociales brésiliennes.

Mots-CLÉs: Pensée sociale brésilienne. Intellectuels. Culture politique, Francisco de Oliveira.

Marco Antonio Perruso - Doutor em Sociologia pela Universidade Federal do Rio de Janeiro. Professor Adjunto de Sociologia da Universidade Federal Rural do Rio de Janeiro. Tem experiência nas áreas de Sociologia e de Ciências Sociais, atuando principalmente nos seguintes temas: pensamento social brasileiro, intelectuais, cultura política, movimentos sociais, sociedade civil, trabalho, globalização e teoria social. Publicações recentes: A temática dos movimentos sociais urbanos no Brasil dos anos 1970/80. Revista Mundos do Trabalho, v. 4, p. 32-56, 2012; Articulações entre intelectuais e movimentos populares nos anos 1970/80. Revista Pós Ciências Sociais, v. 8, p. 175-194, 2011; Em busca do 'Novo': intelectuais brasileiros e movimentos populares nos anos 1970/80. São Paulo: Annablume, 2009. (Menção Honrosa no Concurso Brasileiro de Obras Científicas de 2010 da ANPOCS - Associação Nacional de Pós-Graduação e Pesquisa em Ciências Sociais). 